\title{
Weight Status of 7-Year-Old Hungarian Children between 2010 and 2016 Using Different Classifications (COSI Hungary)
}

\author{
Viktoria Anna Kovacs ${ }^{a} \quad$ Marta Bakacs $^{a}$ Csilla Kaposvari ${ }^{a} \quad$ Eva Illes ${ }^{a}$ \\ Gergo Erdei $^{\mathrm{b}}$ Eva Martos ${ }^{c}$ Joao Bredad \\ a Division of Nutrition Physiology and Epidemiology, National Institute of Pharmacy \\ and Nutrition, Budapest, Hungary; ${ }^{b}$ Division of Applied Nutrition, National Institute of \\ Pharmacy and Nutrition, Budapest, Hungary; ${ }^{c}$ University of Physical Education, Budapest, \\ Hungary; ${ }^{d}$ World Health Organization, European Office for Prevention and Control of \\ Noncommunicable Diseases, Moscow, Russian Federation
}

\section{Keywords}

Body mass index · Children · Thinness · Overweight · Obesity · Hungary $\cdot$ Progress · Weight status

\begin{abstract}
Aims: To describe the prevalence of thinness, overweight, and obesity in Hungarian children (age 7.0-7.9 years) according to different classifications, to assess the progress between 2010 and 2016, and to investigate whether tendencies differ according to gender. Methods: A national representative sample was generated by two-stage cluster sampling, and a total of 2,651 children (50.9\% boys; age $7.49 \pm 0.3$ years) were measured (weight and height) in October 2016. Population estimates were calculated using the WHO, IOTF, and national cut-offs. Results: Prevalence of thinness (including grade 1 and 2) was $12.6 \%$ based on the IOTF criteria and $15.6 \%$ based on the WHO definition. $22.5 \%$ of children were identified as overweight or obese according to the IOTF classification, compared with $28.4 \%$ according to the WHO definition. Between 2010 and 2016, each classification indicated possible stability in overweight and obesity prevalence. In contrast, the prevalence of thinness grade 2 almost doubled in 6 years according to all definitions $(p<0.05)$. No significant gender difference was observed in the progress. Conclusion: Overweight and obesity appeared to be stable over 6 years, but we detected growing thinness rates. Routine collection of high-quality data that are based on standardized and comparable methods is essential to monitor the childhood obesity problem.
\end{abstract}

(C) 2018 The Author(s)

Published by S. Karger $\mathrm{GmbH}$, Freiburg

Viktoria Anna Kovacs, MD PhD

Division of Nutrition Physiology and Epidemiology

National Institute of Pharmacy and Nutrition

Albert Florian u. 3/a, 1097 Budapest, Hungary

kovacs.viktoria@ogyei.gov.hu 


\section{Introduction}

Childhood obesity has major implications on individual and population health $[1,2]$ and on health care systems $[3,4]$. Yet, in many countries the prevalence is increasing [5, 6]. Studies that provide comparable figures on prevalence and time trends help monitor the childhood obesity epidemic. However, in practice, comparability of available data is limited, mainly due to the difference in sample, methodology, and quality of the data [7].

In Hungary, there is a long-standing history of school health examination carried out annually by school nurses in the $2 \mathrm{nd}, 4$ th, 6 th, 8 th, 10 th, and 12 th grades (i.e., at ages of 8,10 , $12,14,16$, and 18 years). These check-ups are mandatory and regulated by law (19/2009 (VI.18) Decree of Minister of Health). Within this procedure, school nurses measure, among others, body height and body weight. However, measuring devices are different and in many cases are not calibrated for years. Moreover, standardized protocols are not always followed, and neither regular training nor other quality assurance or digitalized data procedures are in place. Since prevalence rates were calculated and submitted at school level, a national database with high data quality that allows the monitoring of childhood weight status trends was lacking. Concerning the definition used by the school health system, overweight is considered as BMI $\geq 90$ th but $\leq 97$ th percentile, and obesity is defined as BMI $>97$ th percentile. National growth charts [8] are used for the identification of overweight children. Given these different methods used for collecting and analyzing the data, international comparison is difficult.

These were the reasons why experts and decision makers proposed to join the Childhood Obesity Surveillance Initiative (COSI) of the WHO Regional Office for Europe in 2010. COSI is a collaboration that uses harmonized methodology among participating countries to provide data on standardized weight and height measurements in nationally representative samples of children aged 6-9 years [9]. It has a semi-longitudinal design with repeated cross-sectional samples. COSI also collects data about school environment (mandatory part) and about dietary and activity habits on individual level (voluntary part). The first round of international data collection took place in 2007/2008. Hungary participated in the second and fourth rounds in the academic years of 2009/2010 and 2015/2016, respectively. The aim of this paper was to present the prevalence of thinness, overweight, and obesity in 7-year-old Hungarian schoolchildren in 2016, and to examine progress by comparing data with the previous implementation round in 2010.

\section{Material and Methods}

This school-based survey was performed in autumn 2016 in parallel with other COSI centers across Europe. The study protocol was approved by the Scientific and Research Ethics Committee of the Medical Research Council (61158-2/2016/EKU).

\section{Sampling Design}

The target population was defined as children aged 7.0-7.9 years on September 1,2016. Planned sample size was approximately 3,100 students representing a 7\% sampling rate. The Educational Authority provided the full list of Hungarian primary schools $(\mathrm{N}=3,050)$. We excluded those institutes which did not have 1st grade classes or had merged classes with less than 10 students in the 1 st grade $(N=593)$. Schools for children with special needs $(\mathrm{N}=75)$ and schools who were owned by private persons or companies $(\mathrm{N}=12)$ were excluded. The final sampling frame included 2,370 institutes. A stratified two-stage cluster sampling was used where schools were the primary sampling units (PSUs) and 1st and 2nd grade classes were the secondary sampling units (SSUs). In the first stage, sampling was stratified on counties. Selection probabilities proportional to size were used in each stratum, where size of schools was defined as the number of 1 st grade classes (the sampling frame covered mainly 1st grade pupils). We achieved these probabilities by circular systematic sampling. In this stage, 155 schools were selected, based on an average class size of 20 students and expected 
Kovacs et al.: Weight Status of 7-Year-Old Hungarian Children between 2010 and 2016 Using Different Classifications (COSI Hungary)

consent rate of 0.9. In the second stage, for selecting SSUs we used a simple random sampling, choosing one 1st grade and one 2 nd grade class within each previously selected PSU. Out of 3,111 SSUs, 310 classes were included in the final sample.

\section{Study Procedures}

Study elements at national level contained the anthropometric measurements of children (body height and body weight), the COSI mandatory examiner's record form (paper-based), and the COSI mandatory school record form (electronic). School environmental characteristics were described based on the availability of school playgrounds and extracurricular sport activities, the perceived safety of active commuting to and from the school, nutrition education, marketing of foods high in fat, salt or sugar in school, the presence of fast food restaurants in 500 meters, the possibility of obtaining certain foods and beverages on the school premises, and currently ongoing health promotion activities. This form was completed either by the school principal or by the school clerk.

Invitation letters for the selected schools were sent both to the school principals and to the school nurses responsible for the chosen schools. After agreeing to participate, parents were reached by the school nurses. An opt-out consent approach was used in all schools, meaning that parents who did not want their child to participate were invited to contact the research team.

Fieldwork was carried out with the cooperation of 134 school nurses. Data were collected in a 4-week period between October 3 and October 31, 2016. Measurements followed the COSI standard practice [10]. Prior to data collection, all examiners received a training $\mathrm{CD}$ which contained the description of the measuring tools, assembly guidelines, and a video demonstration of the measurements using WHO standardized techniques.

On the day of the measurement, information about the number of children registered and measured per sampled class, the number of having refused to be measured, and those absent on the day of measurement as well as date and time of measurement (i.e., before or after lunch) were recorded. Besides, on individual level, date of birth, gender, place of living (only the name of the city, town, or village), clothes worn when measured and whether or not breakfast was consumed on that day were recorded. Permission was asked of the child before the measurements and noted. Children were asked to take off their shoes as well as all heavy clothing (coats, sweaters, jackets, etc.) and to remove items such as wallets, mobile phones or key chains. The majority of children were measured either in gym clothes (48.2\%) or in light clothing (40.2\%). Heavy clothing was worn only by $1.3 \%$ of the participants. Body weight was measured to the nearest $0.1 \mathrm{~kg}$ with portable digital (OMRON BF511) scales, and body height was measured standing upright to the nearest 0.1 centimeters (cm) using a 2M wall-mounted stadiometer roll-up height measurer.

An expert from the national coordinating institute verified the completeness of forms; schools with incomplete questionnaires were contacted, and the missing responses were resolved.

\section{Data Processing}

Data was anonymized at the point of data entry. We employed double data entry by two independent data clerks in the case of the examiner's record forms, and used 10\% double entry in the case of school record forms. For data entry EpiData Entry 3.1 was used (www.epidata.dk). In the data entry program, we included in-built verifications (specification of legal values, range checking). We checked the completeness of the entered data, searched for out of range values and examined invalid question skipping. Data entry error rate was less than $0.1 \%$. The exact age of each child was calculated by subtracting the birthdate from the measurement date; then variables with age in years were created. Body weight was adjusted for the weight of clothes worn $(-0.13 \mathrm{~kg}$ for gym clothes, $-0.195 \mathrm{~kg}$ for light clothing and $-0.6 \mathrm{~kg}$ for heavy clothing). Then, BMI $\left(\mathrm{kg} / \mathrm{m}^{2}\right)$ was calculated. Thinness, overweight, and obesity were classified in three ways using the national cut-offs [8], the recently updated International Obesity Task Force (IOTF) criteria [11-13], and the WHO 2007 growth references [14, 15]. As pointed in table 1, WHO definition is based on standard deviation, the IOTF reference builds on an extrapolation from BMI at the age of 18, and the Hungarian definition uses BMI percentiles. Figure 1 show the different BMI cut-offs for thinness, overweight, and obesity for each definition in 7-year-old boys and girls. Population estimates were performed with the SURVEY module of Stata 11.0 software (College Station, TX, USA). By setting the sampling weight and the primary sampling units, the analysis is fitted to these sampling characteristics. Continuous variables are presented with mean and standard errors and weight classifications with percentages and 95\% confidence intervals (95\% CI). The t-test was used for continuous variables, and Pearson's chi square test was used for categorical variables to test gender and time differences between 2010 and 2016. All differences were considered significant at p < 0.05 . 
Kovacs et al.: Weight Status of 7-Year-Old Hungarian Children between 2010 and 2016 Using Different Classifications (COSI Hungary)

Table 1. Definitions for thinness, normal weight, overweight and obesity according to the WHO, IOTF and Hungarian references

\begin{tabular}{llll}
\hline & WHO & IOTF & Joubert \\
\hline Thinness grade 2 & $<-2$ SD & $<17$ & $<$ P3 \\
Thinness grade 1 & $<-1$ SD and $\geq-2$ SD & $<18,5$ and $\geq 17$ & $<$ P10 and $\geq$ P3 \\
Normal weight & $\geq-1$ SD and $\leq 1$ SD & $\geq 18,5$ and $<25$ & $\geq$ P10 and $<$ P90 \\
Overweight & $>1$ SD and $\leq 2$ SD & $\geq 25$ and $<30$ & $\geq$ P90 and $\leq$ P97 \\
Obesity & $>2$ SD & $\geq 30$ & $>$ P97
\end{tabular}

$\mathrm{SD}=$ Standard deviation; $\mathrm{P}=$ Percentile.
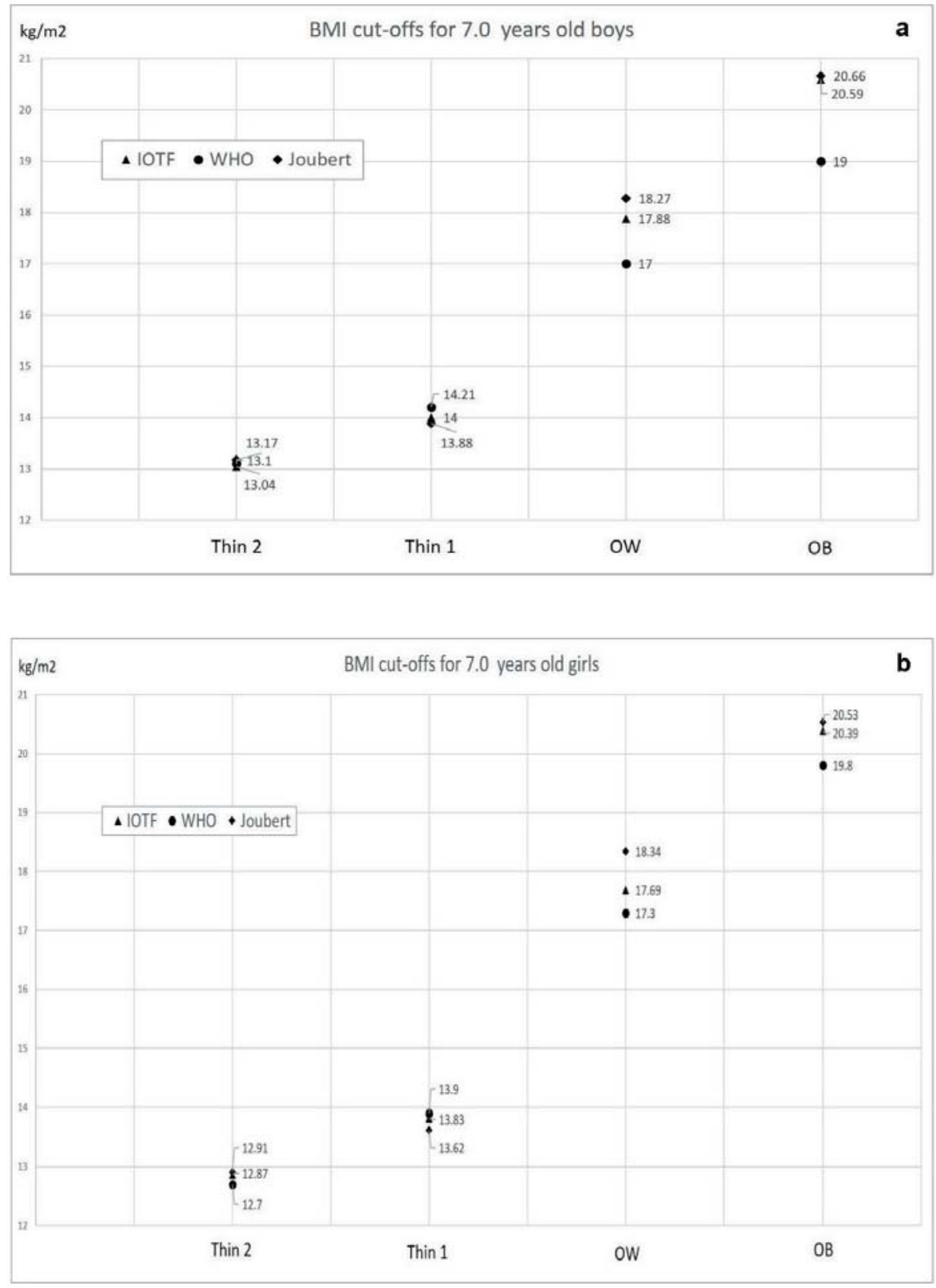

Fig. 1. Comparison of BMI cut-off points for thinness, overweight and obesity according to the IOTF, WHO and Hungarian definitions in a boys and b girls $[8,13,14]$. Thin $1=$ Thinness grade 1 ; Thin 2; thinness grade 2; OW = Overweight; OB = Obesity. Adapted from Kunesova et al., 2011 [16]. 
Kovacs et al.: Weight Status of 7-Year-Old Hungarian Children between 2010 and 2016 Using Different Classifications (COSI Hungary)

Table 2. Anthropometric variables and weight classification in 7-year-old Hungarian schoolchildren evaluated by different cut-offs (based on population estimates)

\begin{tabular}{|c|c|c|c|c|}
\hline & $\begin{array}{l}\text { All children } \\
\text { mean (SE) }\end{array}$ & $\begin{array}{l}\text { Girls } \\
\text { mean (SE) }\end{array}$ & $\begin{array}{l}\text { Boys } \\
\text { mean (SE) }\end{array}$ & $\begin{array}{l}\text { Gender difference } \\
\text { p value* }\end{array}$ \\
\hline Height, cm & $127.1(0.16)$ & $126.6(0.19)$ & $127.7(0.21)$ & 0.000 \\
\hline Weight, kg & $27.1(0.13)$ & $26.9(0.19)$ & $27.2(0.17)$ & 0.241 \\
\hline \multirow[t]{2}{*}{$\mathrm{BMI}, \mathrm{kg} / \mathrm{m}^{2}$} & $16.6(0.07)$ & $16.7(0.09)$ & $16.6(0.09)$ & 0.442 \\
\hline & $\%(95 \% \mathrm{CI})$ & $\%(95 \% \mathrm{CI})$ & $\%(95 \% \mathrm{CI})$ & \\
\hline \multicolumn{5}{|c|}{ Weight classification (Joubert) [8] } \\
\hline Thinness grade 2 & $3.2(2.5 ; 4.1)$ & $2.9(1.9 ; 4.1)$ & $3.5(2.6 ; 4.8)$ & 0.379 \\
\hline Thinness grade 1 & $6.1(5.2 ; 7.2)$ & $5.2(3.9 ; 6.7)$ & $6.9(5.8 ; 8.4)$ & 0.044 \\
\hline Normal weight & $69.9(68.0 ; 71.6)$ & $70.7(68.0 ; 73.3)$ & $69.0(66.5 ; 71.4)$ & 0.350 \\
\hline Overweight ${ }^{\#}$ & $10.3(9.1 ; 11.6)$ & $9.9(8.3 ; 11.9)$ & $10.6(8.9 ; 12.5)$ & 0.609 \\
\hline Obesity & $10.6(9.4 ; 11.9)$ & $11.3(9.5 ; 13.4)$ & $9.9(8,4 ; 11.6)$ & 0.242 \\
\hline \multicolumn{5}{|c|}{ Weight classification (IOTF) [13] } \\
\hline Thinness grade 2 & $2.9(2.2 ; 3.8)$ & $2.9(2 ; 4.2)$ & $2.8(1.9 ; 3.9)$ & 0.846 \\
\hline Thinness grade 1 & $9.7^{\mathrm{a}}(8.4 ; 11.1)$ & $8.9^{a}(7.3 ; 10.9)$ & $10.4^{\mathrm{a}}(8.8 ; 12.2)$ & 0.191 \\
\hline Normal weight & $65.0(63.1 ; 66.8)$ & $64.5(61.8 ; 67.2)$ & $65.4(62.7 ; 68.1)$ & 0.643 \\
\hline Overweight ${ }^{\#}$ & $13^{\mathrm{a}}(11.7 ; 14.5)$ & $13.6(11.6 ; 15.7)$ & $12.5(10.8 ; 14.5)$ & 0.443 \\
\hline Obesity & $9.5(8.3 ; 10.7)$ & $10.1(8.4 ; 11.9)$ & $8.9(7.5 ; 10.5)$ & 0.289 \\
\hline \multicolumn{5}{|c|}{ Weight classification (WHO) [14] } \\
\hline Thinness grade 2 & $2.9(2.2 ; 3.7)$ & $2.1(1.4 ; 3.2)$ & $3.6(2.6 ; 4.9)$ & 0.037 \\
\hline Thinness grade 1 & $12.7^{\mathrm{a}}(11.2 ; 14.4)$ & $11^{\mathrm{a}}(9.2 ; 13.2)$ & $14.3^{\mathrm{a}}(12.5 ; 16.4)$ & 0.009 \\
\hline Normal weight & $56.0(54.0 ; 57.9)$ & $58.3(55.6 ; 61.0)$ & $53.8(51.0 ; 56.6)$ & 0.025 \\
\hline Overweight ${ }^{\#}$ & $14.8^{\mathrm{a}}(13.4 ; 16.3)$ & $16.4^{\mathrm{a}}(14.5 ; 18.5)$ & $13.3(11.3 ; 15.5)$ & 0.037 \\
\hline Obesity & $13.6^{\mathrm{a}}(12.1 ; 15.2)$ & $12.1(10.3 ; 14.3)$ & $15^{\mathrm{a}}(13.1 ; 17.1)$ & 0.028 \\
\hline
\end{tabular}

$\mathrm{BMI}=$ Body mass index; $\mathrm{SE}=$ standard errors; $\mathrm{CI}=$ confidence interval.

* p values are calculated with t test for continuous variables and with Pearson's chi square test for categorical variables.

\#Figures for 'overweight' does not include those for 'obesity'.

asignificant difference $(\mathrm{p}<0.05)$ in comparison with the Hungarian references.

\section{Results}

Out of the total number of 1 st and 2 nd grade children ( 6 to 8 years old) in the 136 participating schools, there were 208 parent refusals, 323 children were absent, and 1 child refused the measurement on the day of the survey. Altogether 5,454 children were measured of which 16 were excluded (height was out of the range of mean \pm 3 SD).

\section{Prevalence of Thinness, Overweight, and Obesity}

This analysis is focusing on children aged 7.00 to 7.99 years. Thus, the current population estimates are based on the representative sample of 2,651 children (mean age 7.49 \pm 0.3 years; $50.9 \%$ boys). Mean height, weight, BMI, and proportions of weight classifications in total and for girls and boys separately are presented in table 2 . Although boys were taller than girls ( $127.7 \pm 0.2 \mathrm{~cm}$ vs. $126.6 \pm 0.2 \mathrm{~cm} ; \mathrm{p}=0.0004)$, their mean weight and BMI did not differ significantly from girls. Overall, depending on the definition, thinness, including grade 1 and 2 , affected $9.3-15.6 \%$ of children, and overweight, including obesity, $20.9-28.4 \%$ of children. The prevalence rates of thinness grade 1 and 2 were higher among boys according to the WHO 
Kovacs et al.: Weight Status of 7-Year-Old Hungarian Children between 2010 and 2016 Using Different Classifications (COSI Hungary)

criteria. Also, boys had higher thinness grade 1 prevalence using the national cut-offs. Besides, there were significant gender differences both in the prevalence of overweight $13.3 \%$ in boys vs. $16.4 \%$ in girls; $p=0.037$ ) and obesity ( $15 \%$ in boys vs. $12.1 \%$ in girls; $p=0.028$ ) based on the WHO classification, but not according to the other two definitions.

\section{Comparison of Different Classification Methods}

Differences in BMI cut-off points for the three definitions were reflected in the prevalence rates. Depending on which growth reference we used, the prevalence of thinness, including grade 1 and 2, varied from 10.4 to $17.9 \%$ for boys and from 8.1 to $13.1 \%$ for girls, while the prevalence of overweight, including obesity, ranged from $20.5 \%$ to $28.3 \%$ for boys and from $21.2 \%$ to $28.5 \%$ for girls. We found a significant difference in the prevalence of thinness grade 1 between the IOTF and WHO definition in comparison with the Hungarian references $(9.7 \%$ and $12.7 \%$ vs. $6.1 \%$ ). In addition, both the prevalences of overweight and obesity were the highest when using the WHO definition. In some cases, the prevalence of obesity exceeded the prevalence of overweight (e.g. when using the national classification in girls or using the WHO classification in boys).

\section{Progress in Weight Status}

Overall, each weight classification indicated possible stability in overweight and obesity prevalence between 2010 and 2016 (table 3). In contrast, the prevalence of thinness grade 2 almost doubled in 6 years according to all definitions $(\mathrm{p}<0.05)$. In boys, the prevalences of thinness, overweight, and obesity tended to slightly increase according to each reference. On the contrary, decreasing tendencies were observed in girls in thinness grade 1 and in overweight prevalence, while the rate of thinness grade 2 and obesity appeared to increase a bit. These differences, however, were not statistically significant.

\section{Discussion}

In the current study, based on standardized objective measurements of height and weight, the prevalence of overweight including obesity was $20.9 \%$, and obesity was found in one tenth of 7-year-old Hungarian schoolchildren according to the national criteria. In order to be comparable to other studies, we also used two international BMI classification systems. $22.5 \%$ of children were identified as overweight or obese according to the IOTF classification, compared with $28.4 \%$ according to the WHO definition. Similar to the results reported herein, other studies also showed variations in the prevalence of overweight or obesity when using different weight classifications [16-19]. In this study, the prevalence of overweight was by $2.8 \%$ higher in girls and by $0.8 \%$ higher in boys according to the WHO definition, while the rate of obesity was by $2 \%$ higher in girls and by $6.1 \%$ higher in boys compared to the IOTF criteria. This reflects that the highest difference between the IOTF and WHO cut-offs can be seen in obesity in boys (fig. 1). Since the prevalence of overweight and obesity varies depending on the definition, presentation of results according to internationally accepted criteria such as the IOTF or WHO is necessary to improve comparison and to properly assess time trends. Presenters should clearly state which definitions were used. Besides, one should be cautious when comparing results based on different references. Also, readers should be aware that a false drop or increase in the prevalence may appear if one reference is compared to another [20].

Beyond the above concerns of comparing data using different references, comparison is also hampered by other relevant factors when we assess our results against the available Hungarian data. First, only a few studies exist on the prevalence of overweight among 
Kovacs et al.: Weight Status of 7-Year-Old Hungarian Children between 2010 and 2016 Using Different Classifications (COSI Hungary)

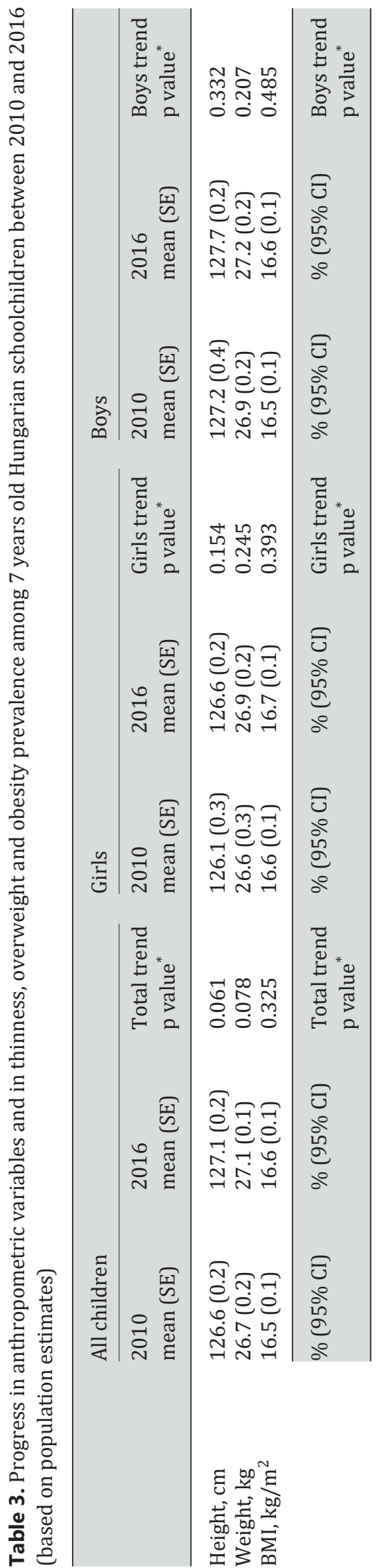

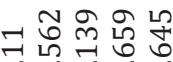
○ั Ұ

๑ร

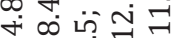
○்

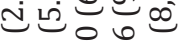
ஸे 강 สำก

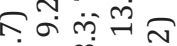
ஸे बं

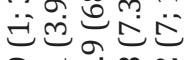

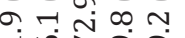
늘유

$$
\text { m }
$$

조ํ

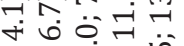
б̆ бळ ¿ $\underbrace{0} \underbrace{a}_{m}$ สิ ํํำ

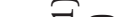
ศิ์ กิ์

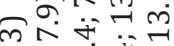
के ¿ $\underbrace{\infty} \underbrace{\infty}$ 눙 เ

ㄴํํำํำ 웅두

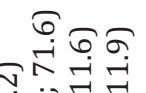
Nㅜ음

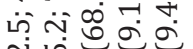
ง v $\underbrace{}_{0} \underbrace{}_{0}$

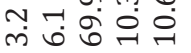<smiles></smiles>
สลํำ ำ क 氙等

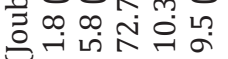
I $N-$ 总茎造 造 थै थैं 记苞焉

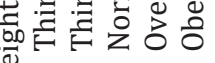

귀 సิำ ००००00 가

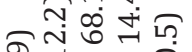
ले ने कुष ¿ $\underbrace{\infty}$ ஸ ㄴํำ กี่

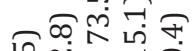

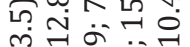
के تु नु @心 人 0 तबंबु

ㄴํㄴำ ำ . กิธ

สํำ สุ m अं ¿ $\underbrace{e}_{0} \underbrace{\infty}_{0}$ $\sigma a$; ง $\infty$ bु โกุก

ก ด

๓ี่ $\infty 00$ e $\underbrace{0} \underbrace{}_{0}$

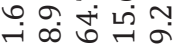

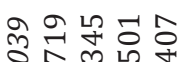
0000 ( ㄱํำ กิ ๓ 표무 త กิ ลิ เู่ ตั ๙그

ร ๓ $\sigma$ ำ

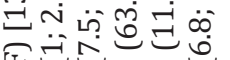

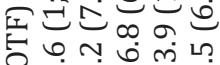
○ِ

\section{I $\sim$}

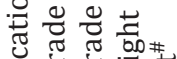
क⿺辶万人 嵌

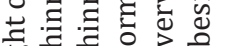

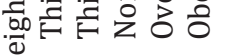

ㅇํㄱㄷํㅇ 웅둥 ร6ธ 눈 뉵 +

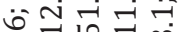
글 o $\dot{m} \dot{m}$ สำก ตั त mं б m م.

œ 뀌ำ ○० 000 อกิก จิธี m $\dot{m} \dot{\omega} \ddot{m}$ 讨 $\exists \sigma \underbrace{2}=$ 걱다웜

अ요저

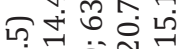
ง $\because$ ஸे ஸึ่ $e_{+\rightarrow r}$ 검얻ㅇ

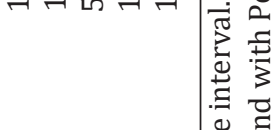

ฟิ

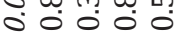
ซสฺก + 건 읙 लं i తป 己 ดे

$\infty \approx \approx$

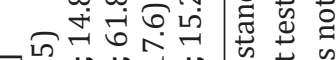
Fণ্்

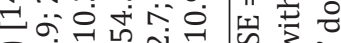

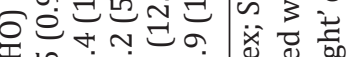
约 원

ป $N$

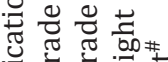
छั

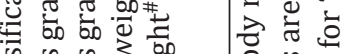

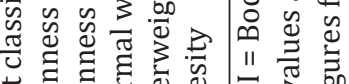

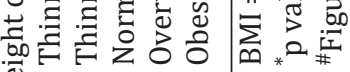


Kovacs et al.: Weight Status of 7-Year-Old Hungarian Children between 2010 and 2016 Using Different Classifications (COSI Hungary)

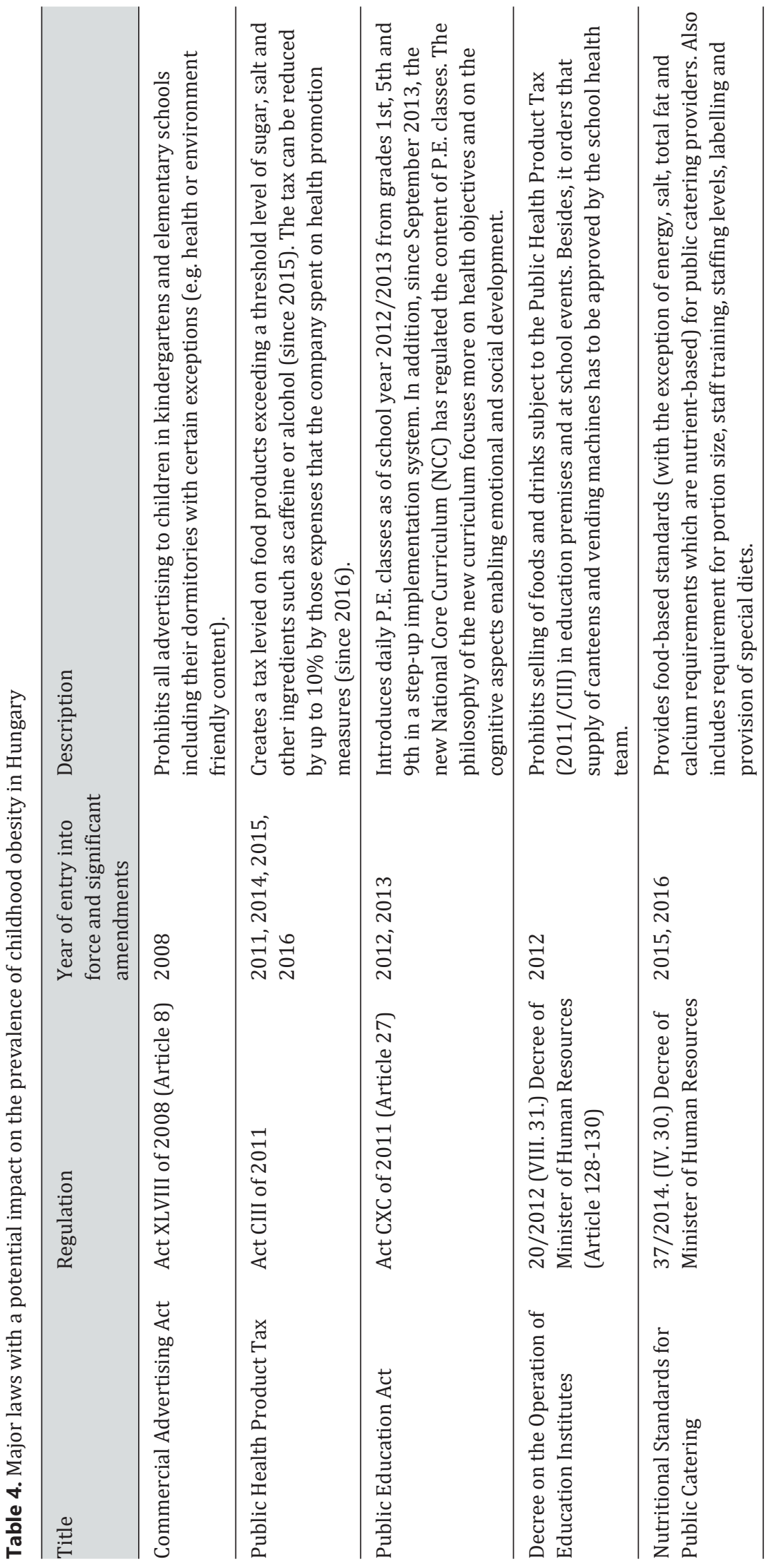


Kovacs et al.: Weight Status of 7-Year-Old Hungarian Children between 2010 and 2016 Using Different Classifications (COSI Hungary)

Hungarian children that are based on measured data [21-25]. Second, study samples vary from a representative sample of primary school children aged 7-14 years from Budapest [22] through a national representative sample of boys aged 6.51-10.5 years [21] to the 2 nd Hungarian National Growth Survey 2003-2006 (national representative sample of 24,888 children aged 3-18 years) [23]. All these works used the IOTF growth reference from 2000. Finally, these studies were carried out more than 10 years ago.

As COSI provides comparable figures among the participants, we matched our results to other Central European COSI countries in the same implementation round (unpublished data). In Croatia, the prevalence of overweight was $21.6 \%$ in boys and $20.3 \%$ in girls, and the obesity prevalence was $17.1 \%$ for boys and $10.7 \%$ for girls. These rates are higher than what we have found in Hungary. For Slovakia, the prevalences were similar to Hungary. The overweight and obesity rates were $16.5 \%$ and $13.8 \%$ for boys and $13.5 \%$ and $10.7 \%$ for girls. In Romania, although the results are not directly comparable to our study because of the difference among participant ages (i.e., 8.0-8.99 years in Romania), the prevalence was lower than in other countries in the Region. Overweight occurred in $10.5 \%$ of boys and $8.9 \%$ of girls, while obesity was found only in $5.1 \%$ of boys and $5.4 \%$ of girls. All these results are calculated according to the WHO definition. Several environmental (e.g., school nutritional environment, higher exposure to marketing, or lower number of physical education classes) or cultural factors could be considered to explain this diversity in the prevalence which will be further analyzed in an upcoming paper to provide a deeper understanding about the identified similarities and differences.

Another added value of COSI is the possibility to assess the trends in childhood obesity prevalence both at national and European level. In the present study we found high (i.e., 1 in 4 or 1 in 5, depending on the definition) but possible stable prevalence rates both for overweight and obesity from 2010 to 2016 . This favorable finding may be partly the result of the legislative measures introduced in Hungary in the last few years (table 4). Childhood obesity has apparently plateaued in some COSI countries (e.g., in Sweden or Spain) or even decreased in others (e.g., in Italy or Ireland) [26]. However, trends in subgroups may differ. In our study, we did not find any sex difference. As we did not collect data about the socio-economic status at individual level, we were not able to analyze the prevalence by socio-economic factors. Earlier studies that indicated overall stable prevalence, however, observed differences according to socio-economic status. One study in Sweden indicated some increase both in overweight and obesity in Swedish boys living in less advantaged areas while the overall rate remained stable [27]. A socio-economic gradient was also observed in the Irish COSI study where the overall decrease in overweight was not observed in children coming from disadvantaged schools [28]. The result that the prevalence of the more severe form of thinness has almost doubled in 6 years needs further investigation to identify factors behind the phenomenon. Obesity and thinness in low-income countries have been shown to coexist within families and in poorer groups, and this is thought to point towards similar causal mechanisms related to diet, physical activity, and socio-demographic environment [29]. Another factor can be that even young children idealize a thinner body shape and have a good notion of dieting as a way of achieving it [30], which is also a cause for concern. Policies for prevention of thinness should be considered.

\section{Acknowledgements}

We thank the children who participated in the study and their parents and teachers for their collaboration. We also thank the schools for their support to the study and the responsible school nurses for carrying out the measurements. We are very grateful for the Hungarian School Sport Federation for providing the 
Kovacs et al.: Weight Status of 7-Year-Old Hungarian Children between 2010 and 2016 Using Different Classifications (COSI Hungary)

equipment for the measurements. We also thank to the COSI Principle Investigators in Croatia, Romania and Slovakia for sharing their preliminary data. The study was partially supported by the WHO Regional Office for Europe (Biannual Collaborative Agreement 2016/2017).

\section{Author Contributions}

V.A.K. is the principal investigator for COSI Hungary and drafted the manuscript. B.M. and E.I. conducted the statistical analyses. E.G. supported the data collection. E.M. supervised the data collection in 2010 and critically revised the manuscript. Cs.K. and J.B. critically revised the manuscript. All authors had final approval of the submitted version. JB is a staff member of the World Health Organization Regional Office for Europe. The author is responsible for the views expressed in this publication and they do not necessarily represent the decisions or stated policy of WHO.

\section{Disclosure Statement}

The authors declare no conflict of interest.

\section{References}

1 van Vliet M, Heymans MW, von Rosenstiel IA, Brandjes DP, Beijnen JH, Diamant M: Cardiometabolic risk variables in overweight and obese children: a worldwide comparison. Cardiovasc Diabetol 2011;10:106.

2 Dietz WH: Overweight in childhood and adolescence. N Engl J Med 2004;350:855-857.

-3 Grant-Guimaraes J, Feinstein R, Laber E, Kosoy J: Childhood overweight and obesity. Gastroenterol Clin North Am 2016;45:715-728.

4 Sonntag D, Ali S, De Bock F: Lifetime indirect cost of childhood overweight and obesity: a decision analytic model. Obesity (Silver Spring) 2016;24(1): 200-206.

5 Wang Y, Lobstein T: Worldwide trends in childhood overweight and obesity. Int J Pediatr Obes 2006;1:11-25.

-6 Howe LD, Firestone R, Tilling K, Lawlor DA: Trajectories and transitions in childhood and adolescent obesity; in Burton-Jeangros C, Cullati S, Sacker A, Blane D (eds): Source A Life Course Perspective on Health Trajectories and Transitions. Cham, Springer, 2015, chapter 2.

-7 Ahrens W, Pigeot I, Pohlabeln H, De Henauw S, Lissner L, Molnár D, Moreno LA, Tornaritis M, Veidebaum T, Siani A; IDEFICS Consortium: Prevalence of overweight and obesity in European children below the age of 10. Int J Obes (Lond) 2014;38(suppl 2):S99-107.

8 Joubert K, Darvay S, Gyenis Gy, Elteto O, Mag K, van't Hof M, Agfalvi R: The National Longitudinal Child Growth Study: results from birth to 18 years of age. Budapest, Hungary: 83rd Central Statistical Office Population Science Statistical Research Report, 2006.

-9 Wijnhoven TM, van Raaij JM, Spinelli A, Rito AI, Hovengen R, Kunesova M, Starc G, Rutter H, Sjöberg A, Petrauskiene A, O'Dwyer U, Petrova S, Farrugia Sant'angelo V, Wauters M, Yngve A, Rubana IM, Breda J: WHO European Childhood Obesity Surveillance Initiative 2008: weight, height and body mass index in 6-9-year-old children. Pediatr Obes 2013;8:79-97.

10 World Health Organization: Training Course on Child Growth Assessment. Geneva, WHO, 2008.

11 Cole TJ, Bellizzi MC, Flegal KM, Dietz WH: Establishing a standard definition for child overweight and obesity worldwide: international survey. BMJ 2000;320:1240.

12 Cole TJ, Flegal KM, Nicholls D, Jackson AA: Body mass index cut offs to define thinness in children and adolescents: international survey. BMJ 2007;335:194.

13 Cole TJ, Lobstein T: Extended international (IOTF) body mass index cut-offs for thinness, overweight and obesity. Pediatr Obes 2012; 7:284-294.

14 de Onis M: Development of a WHO growth reference for school-aged children and adolescents. Bull World Health Organ 2007;85:660-667.

15 World Health Organization: WHO Reference 2007. Growth reference data for 5-19 years. www.who. int/ growthref/en/ (last accessed May 8, 2018).

16 Kunešová M, Vignerová J, Pařízková J, Procházka B, Braunerová R, Riedlová J, Zamrazilová H, Hill M, Bláha P, Steflová A: Long-term changes in prevalence of overweight and obesity in Czech 7-year-old children: evaluation of different cut-off criteria of childhood obesity. Obes Rev 2011;12:483-491.

-17 Kêkê LM, Samouda H, Jacobs J, di Pompeo C, Lemdani M, Hubert H, Zitouni D, Guinhouya BC: Body mass index and childhood obesity classification systems: a comparison of the French, International Obesity Task Force (IOTF) and World Health Organization (WHO) references. Rev Epidemiol Sante Publique 2015;63:173-182. 
Kovacs et al.: Weight Status of 7-Year-Old Hungarian Children between 2010 and 2016 Using Different Classifications (COSI Hungary)

18 Nilsen BB, Yngve A, Sjöberg A, Moraeus L, Lissner L, Werner B: Using different growth references to measure thinness and overweight among Swedish primary school children showed considerable variations. Acta Paediatr 2016;105:1158-1165.

19 World Health Organization: Comparison with IOTF cut-offs. www.who.int/growthref/comparison_iotf. $p d f ? u a=1$ (last accessed May 8, 2018).

20 Rolland-Cachera MF: Childhood obesity: current definitions and recommendations for their use. Int J Pediatr Obes 2011;6: 325-331.

21 Prókai A, Mészáros J, Mészáros Z, Photiou A, Vajda I, Sziva A: Overweight and obesity in 7 to 10-year-old Hungarian boys. Short communication. Acta Physiol Hung 2007;94:267-270.

22 Antal M, Péter S, Biró L, Nagy K, Regöly-Mérei A, Arató G, Szabó C, Martos E: Prevalence of underweight, overweight and obesity on the basis of body mass index and body fat percentage in Hungarian schoolchildren: representative survey in metropolitan elementary schools. Ann Nutr Metab 2009;54:171-176.

-23 Bodzsár ÉB, Zsákai A: Body developmental status of Hungarian children and adolescents - Hungarian National Growth Study 2003-2006. 2012. http://antropologia.elte.hu/onv.pdf (last accessed May 8, 2018).

24 Zsakai A, Jakab K, Karkus Zs, Toth K, Kern B, Vitalyos AG, Lichthammer A, Balazsi Sz, Gabor Zs: New Hungarian national cut-off points of BMI for screening childhood underweight, overweight and obesity. Anthropologiai Közlemények 2007;48:21-30.

25 Kern B: The prevalence of overweight and obesity in Hungarian children. EAA Summer School eBook 1:181186. 16-30 June, 2007, Prague, Czech Republic. http://eaa.elte.hu/Kern.pdf(last accessed May 8, 2018).

26 Moreaus L, Lissner L, Sjöberg A: Stable prevalence of obesity in Swedish schoolchildren from 2008 to 2013 but widening socio-economic gap in girls. Acta Paediatr 2014;103:1277-1284.

27 Sjöberg A, Lissner L, Albertsson-Wikland K, Marild S: Recent anthropometric trends among Swedish school children: evidence for decreasing prevalence of overweight in girls. Acta Paediatr 2008;97:118-123.

28 Heinien M, Murrin C, Daly L, O’Brien J, Heavey P, Kilroe J, O’Brien M, Scully H, Mulhern LM, Lynam A, Hayes C, O'Dwyer U, Eldin N, Kelleher C: The Childhood Obesity Surveillance Initiative (COSI) in the Republic of Ireland: findings from 2008, 2010 and 2012. Dublin, Health Service Executive, 2014.

29 Pearce A, Rougeaux E, Law C: Disadvantaged children at greater relative risk of thinness (as well as obesity): a secondary data analysis of the England National Child Measurement Programme and the UK Millennium Cohort Study. Int J Equity Health 2015;14:61.

30 Schur EA, Sanders M, Steiner H: Body dissatisfaction and dieting in young children. Int J Eat Disord 2000;27: 74-82. 